\title{
Scopes and threats of Mobile Financial services in Bangladesh
}

\author{
Md. Razib Siddiquie \\ (Department of Business Administration, University of Asia Pacific, Bangladesh)
}

\begin{abstract}
Mobile financial service (MFS) is getting popular everyday in Bangladesh. Mobile financial service is a tool to facilitate people with legitimate transaction process without the help of conventional banking system. This service is available through the mobile phone network, thus it may cover the remotest location of a country with least possible cost incurred. This service is very effective in a country that is geographically challenged like Bangladesh, Kenya, and Nigeria etc. And the world has already seen the result; M-Pesa (Mobile financial services in Kenya) is the largest MFS Company in the world. The essence of this service eventually make the number of transactions and amount humongous. The scope of MFS has not yet been explored properly in Bangladesh. If explored properly this can well be one of the biggest industry in Bangladesh which may help her reducing existing unemployment problem to an extent. There are some threats related to this service such as money laundering, corruption. I have done my research on this for last three years and finally prepared this paper.
\end{abstract}

Keywords: Mobile Financial Service, Telecom operator, Bank, Regulation, Scope

\section{Introduction of Mobile Financial Services in Bangladesh:}

Bangladesh is densely populated developing third world country. It has a land area of 56,977 square miles with 170 million people. The education level here in Bangladesh is not that rich. Here per capita GDP is $1,044 \$$ which is $150^{\text {th }}$ in the world. Most of the people living here in rural and doing agriculture related work for their living. There are six major cities in Bangladesh where people from all over the country come for earning their living. Thus every month end they send money back to their home by difference means such as post office, courier, through another person etc. Most of the medium mention here is not secure enough and legitimate. So the need was there to send money properly and legitimately back to their home.

Few visionaries from Bangladesh were observing this for a long time and were trying hard to find a solution to this sensitive issue. Finally they found a solution, but they were afraid about the execution of this new process as the literacy level of our country is not up to the mark. Most of the people are far away from the technological development of the current world.

Finally in early 2010 through Bangladesh bank permission Dutch Bangla Bank launched the long awaited solution and that is mobile financial service (MFS) through mobile network. And the revelation begins from then.

Unlike from other courtiers of the world Bangladesh choose Bank lead Mobile financial service model. In this model Banks will be in the driving seat tagged with telecom operators to run the show. The government of Bangladesh took this decision by taking the money laundering issue as the prime consideration.

Bangladesh Bank then issued license to 28 commercial banks to launch mobile financial services in Bangladesh. And 19 banks are providing the service in the market (Source: Bangladesh Bank website). Later they cancelled license of three of the banks for some regulatory grounds. Now there are 25 banks that are authorized to provide this service in the market.

Banks alone cannot provide this service; telecom operators are one of the key important factors to start the operation. Most of the operators understood this at a very primary stage of MFS operation, that's why they forced the banks to get into a contract that facilitates the telecom operators significantly. They are charging very rates to the banks to operate. Recently Bangladesh bank identifies this anomaly, and they are taking proper measures to rectify this issue.

In Bangladesh this service is getting popular every day. Having introduced in early 2010, it has already become one of the largest Industry of this country.

\section{Methodology:}

I have chosen to interview few employees of the first and second MFS operators to have clear insight about the industries positives and negative of the industry. I also did a survey by interviewing few MFS customers to find out the opportunity and treats of this service. Various statistical and analytical methods were used to process the primary data into presentable and understandable format. 
III. Mobile Financial Services operators in Bangladesh:

The list is as follows;

\begin{tabular}{|l|l|}
\hline Bank Name & Brand Name \\
\hline Brac Bank Limited & bKash \\
\hline Dutch Bangla Bank Limited & Dutch Bangla Bank Mobile Banking \\
\hline ONE Bank Limited & OK \\
\hline United Commercial Bank Limited & Ucash \\
\hline Mecantile Bank Limited & MyCash \\
\hline Prime Bank Limited & Prime Cash \\
\hline Bangladesh Commerce Bank & Sure Cash \\
\hline National Creit \& Commerce Bank Limited & Sure Cash \\
\hline First Security Islami Bank & Sure Cash \\
\hline IFIC Bank & IFIC Mobile Bank \\
\hline Islami Bank Limited & Mcash \\
\hline Trust Bank Limited & Trust Bank Mobile Money \\
\hline AB Bank Limited & yet not declared \\
\hline The City Bank Limited & yet not declared \\
\hline Eastern Bank Limited & yet not declared \\
\hline Dhaka Bank Limited & yet not declared \\
\hline Al Arafa Islami Bank & yet not declared \\
\hline EXIM Bank Limited & yet not declared \\
\hline Bank Asia Limited & yet not declared \\
\hline
\end{tabular}

Amongst all of them bKash is leading the market by a big margin, Dutch bangle bank mobile banking is current holding the second position. Other banks do not have any significant mentionable contribution. bKash got a subscriber base of 10 million plus with 150 million taka worth of daily transaction every day. The service charges for bKash are as follows,

Cash in----0\%

Cash Out---1.85\%

Payment---0\%

Send Money----5 taka (source: bKash website)

Dutch Bangla Bank Mobile Banking has 4.5 million subscribers with 50 million taka worth of transaction every day. The service charges for Dutch Bangla Bank Mobile Banking are as follows,

Cash in----1.0\%

Cash Out---1.0\%

Payment---0\%

Send Money----10 taka (source: Dutch Bangla Bank limited's website)

\section{An overview of MFS in Bangladesh in 2013:}

At the starting of the year the agent number was 59,559 and at the end of the year the number grows to $1,88,647$. The growth ratio is $316.7 \%$ which is remarkable. By looking at this figure one can easily predict that the popularity of MFS in Bangladesh.

At the starting of the year the subscriber number was 5 million and at the end of the year the number grows to 13.87 million.

At the starting of the year the number of transaction was $95,74,382$ and at the end of the year the number grows to $3,13,62,895$.

At the starting of the year the transaction amount was 23202.0 million and at the end of the year the number grows to 66426.1 million.

By looking at the trend, it was identified that cash in, cash out and the send money are the most popular amongst all the transaction types. (Source: Bangladesh bank website)

\subsection{Secure Transaction System:}

\section{Findings:}

Transacting through mobile financial service is very secure. There is no cash handling risk. This is one of the primary reasons behind MFS's success in Bangladesh. Many organizations is adopting this process to transfer cash one place to another securely.

\subsection{Swiftness:}

Transacting through mobile financial service needs significantly less amount of time which is almost negligible. It normally takes 30 seconds to one minute to complete a transaction. Compare to traditional banking or other transactional process, this process is way ahead for comparison. 


\subsection{Convenient:}

Transacting through mobile financial service is very convenient. This transaction is possible $24 / 7$, there is no time boundary. In conventional process if somebody wants to transact money he needs to do it within the working hour of a regular working day which sometimes becomes very inconvenient. Mobile financial services help people doing transaction after office hour, even in weekends as well.

\subsection{Coverage:}

Traditional banking system suffers from poor coverage, only $13 \%$ of the total population can avail banking services. That means $87 \%$ of the population is unbanked.

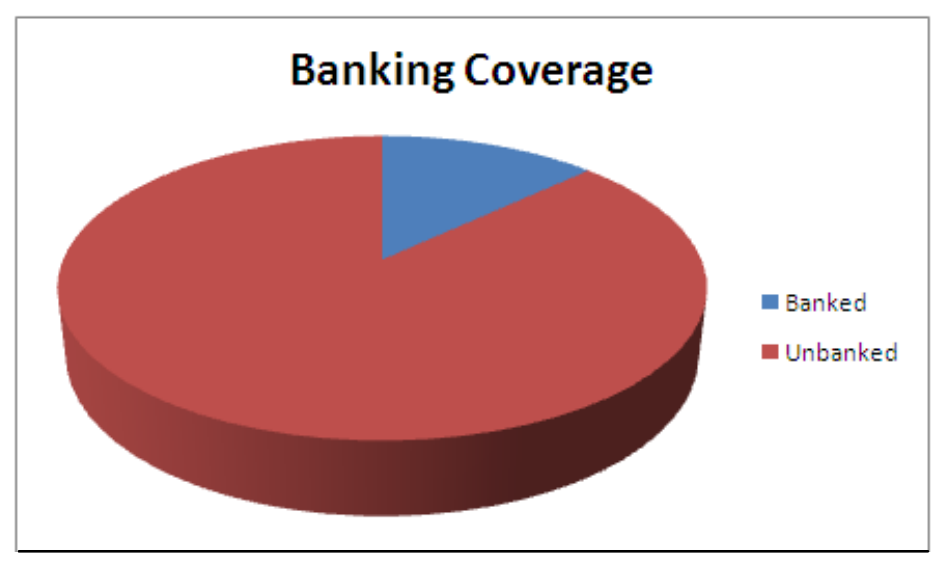

On the other hand almost $95 \%$ of the population uses mobile phone, which is pre-requisite for mobile financial service. It portrays that $95 \%$ of the population can be served with structured transactional process through mobile financial service.

\subsection{Belief:}

\section{Limitations:}

People living in rural have limited access to information technology. Thus they have limited trust on technology. In this scenario acceptance of virtual money instead of hard cash is difficult proposition

\subsection{Error rectification:}

If one person sends money to other wrongly, there is no way the person can get the money back unless the other person send-back the money to him. The population who is basically using MFS is not that educated, as a result the possibility of typing error is high.

\subsection{Charging:}

The charges of MFS are very high compare to conventional banking system. And this is one of the prime constraints on the way of MFS popularity in Bangladesh.

\subsection{Medium of communication:}

In MFS system the transaction takes place trough mobile phones and the process is completely in English. By taking our educational level into consideration, communicating in process which is in English is not convenient at all.

\subsection{Regulatory constraints}

Absence of supportive policies, guidelines, rules and regulations relating to e-transactions are barrier to development in MFS. There are 19 banks already launched their service in the market,

but till now no interbank transaction guideline or regulation policy established among those. So, it's not possible to avail the MFS facilities of bkash through DBBL or TBL. As no supportive mobile transaction policy is available it's very easy to involve in money laundering activities.

\section{Scopes and threats of Mobile Financial services in Bangladesh}

The scope of mobile financial services in Bangladesh is humongous. As a third world developing country Bangladesh is getting donations from around the globe. This fund is being disbursed to the beneficiaries through different channels. Most of the funds drain out before reaching the ultimate beneficiaries, because there is no proper monitoring system available to monitor disbursement. MFS may play a very crucial role to resolve this issue by providing report to the proper authority after every disbursement.

MFS may facilitate our most promising Readymade garments (RMG) sector with more productivity with the existing setup. Garments worker receive their salaries in the form of cash every month. Giving away cash to the workers is a very time consuming process and it normally wastes half of a working day every month. 
By looking at the number of RMG factories in Bangladesh, we can easily conclude that RMG sector is losing billions for this half day break every month. With the help of MFS RMG sector may eliminate this loss completely. This process is applicable where there is factory based manufacturing operations.

Our pharmaceuticals industry is suffering badly from cash handling. Every month they need to pay damarage in the form of lost money, people fled with money, mobbing, robbing etc. MFS has the capability to eliminate these issues completely from their financial ecosystem.

Most of the big distribution companies like Unilever, Marico, Reckit Benkizer, Pran, Akij are suffering from the issues mentioned above. And MFS may help them overcoming those issues.

There so many other scopes in various dimension are available for MFS in Bangladesh.

\section{Suggestion:}

- The MFS operators should take necessary steps to spread the agent network as remotely as possible.

- They should make sure the agents are holding enough cash to facilitate customers with proper services

- The operators should take proper steps to make the entire transaction process in Bangla

- As MFS is dealing with mostly ultra poor people, the operators should reconsider their charging

- Government organizations should implement MFS to disburse funds to beneficiaries that will bring complete transparency to the money handling system.

\section{Conclusion:}

Mobile financial service has a huge scope in Bangladesh. Currently only $7 \%$ of the population is using this service. This service opens the separate era for existing banks and financial institutions. More and more people are coming under the mobile financial service's umbrella everyday. With proper guideline and policies MFS can take Bangladesh to different level of prosperity.

\section{References}

[1]. Sharma, Prerna \& Singh, Preeti (2009): "Users' perception about mobile banking- with special reference toIndore \& around", Review of Business \& Technology Research, Vol. 2, 1, 1-5.

[2]. Cheney, J. S. (2008): “An Examination of Mobile Banking and Mobile Payments: Building Adoption as

[3]. Experience Goods". Available at: www.philadelphiafed.org/pcc/papers/2008 [Accessed: 10 May 2012].

[4]. Black, N. J., Lockett, A., Ennew, C., Winklhofer, H. \& McKechnie, S. (2002): "Modelling consumer

[5]. choice of distribution channels: an illustration from financial services", International Journal of

[6]. Bank Marketing, 20 (4), 161-173.

[7]. Al-Ashban, A.A. \& Burney, M.A. (2001): "Customer adoption of tale-banking technology: the case of

[8]. Saudi Arabia", International Journal of Bank Marketing, 19 (5), 191-200.

[9]. Barnes, S.J., Corbitt, B. (2003): "Mobile banking: concept and potential”, International Journal of Mobile

[10]. Communications, 1 (3), 273-288.

[11]. Islam, Alam, (2010): "Exciting Developments in Mobile Phone Remittance: A Road to Digital

[12]. Bangladesh", BUBT Journal, 3, 127-135.

[13]. Mattila, M. (2003): "Factors affecting the adoption of mobile banking services", Journal of Internet

[14]. Banking and Commerce, 8 (1), 101-119.

[15]. Bangladesh Bank website (www.bangladesh-bank.org) 